Supplement of Atmos. Chem. Phys., 18, 2443-2460, 2018

https://doi.org/10.5194/acp-18-2443-2018-supplement

(C) Author(s) 2018. This work is distributed under

the Creative Commons Attribution 4.0 License.

(c) (1)

Supplement of

\title{
Global sensitivity analysis of GEOS-Chem modeled ozone and hydrogen oxides during the INTEX campaigns
}

Kenneth E. Christian et al.

Correspondence to: Kenneth E. Christian (kenneth-christian@uiowa.edu)

The copyright of individual parts of the supplement might differ from the CC BY 4.0 License. 

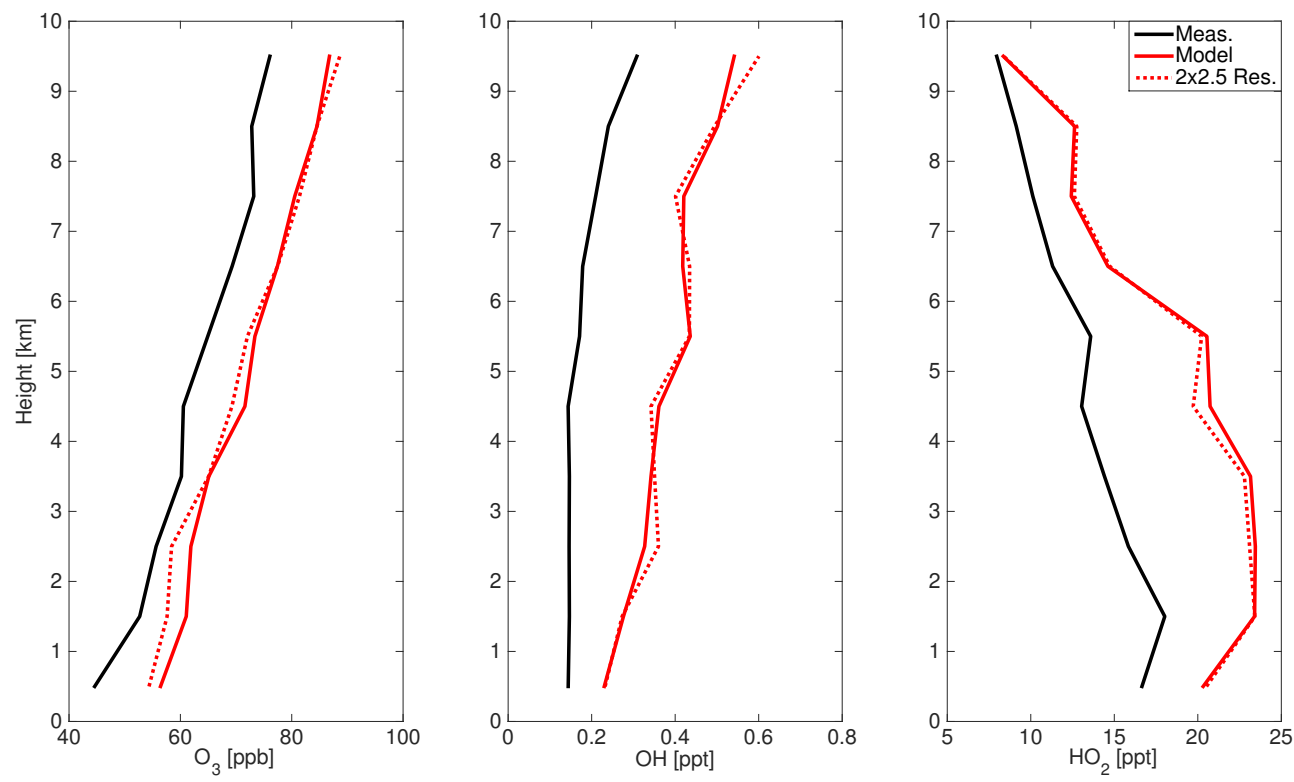

Figure S 1. Vertical profile for $4^{\circ} \times 5^{\circ}$ median modeled (red solid), $2^{\circ}$ × $2.5^{\circ}$ median modeled (red dotted) and median measured (black) $\mathrm{O}_{3}, \mathrm{OH}$, and $\mathrm{HO}_{2}$ for INTEX-A flight data binned by kilometer.
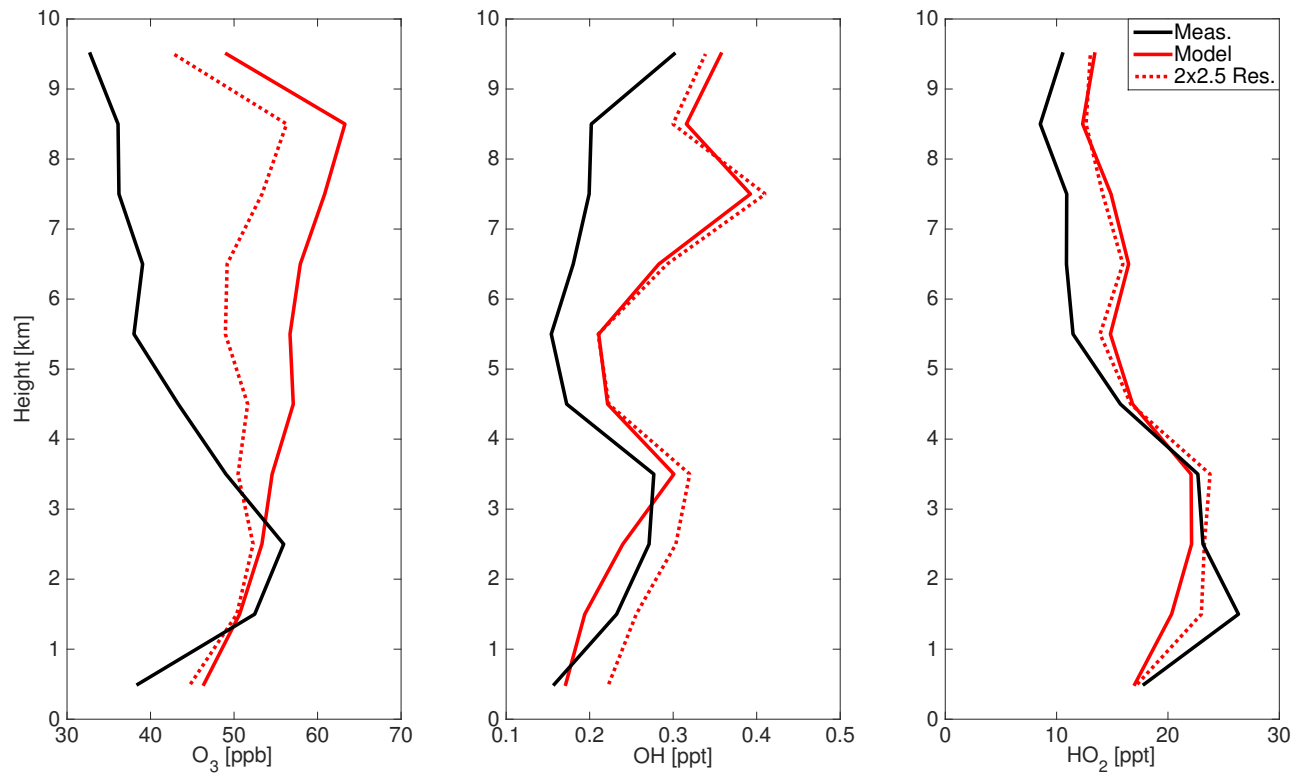

Figure S 2. Vertical profile for $4^{\circ}$ x $5 d$ median modeled (red solid), $2^{\circ}$ x $2.5^{\circ}$ median modeled (red dotted) and median measured (black) $\mathrm{O}_{3}, \mathrm{OH}$, and $\mathrm{HO}_{2}$ for Houseon based INTEX-B flight data binned by kilometer. 

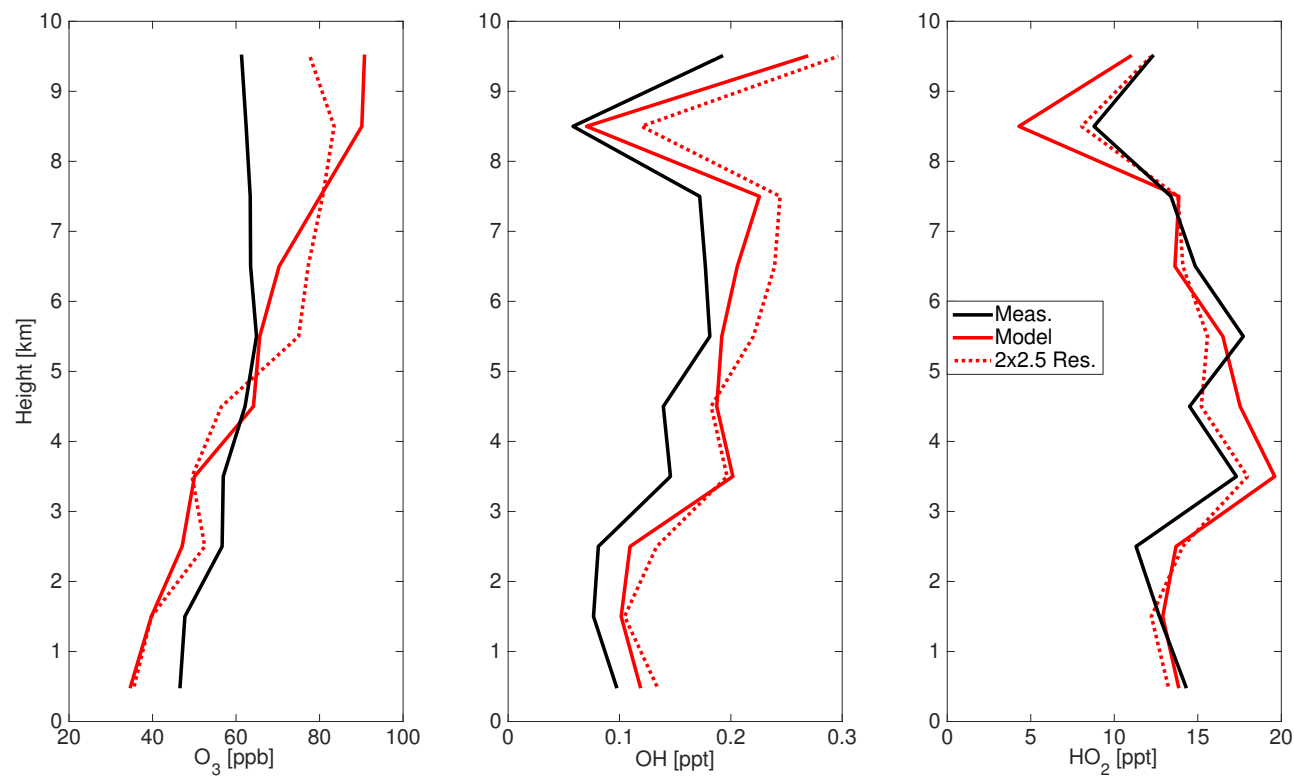

Figure S 3. Vertical profile for $4^{\circ}$ x $5^{\circ}$ median modeled (red solid), $2^{\circ}$ x $2.5^{\circ}$ median modeled (red dotted) and median measured (black) $\mathrm{O}_{3}, \mathrm{OH}$, and $\mathrm{HO}_{2}$ for Honolulu Based INTEX-B flight data binned by kilometer.
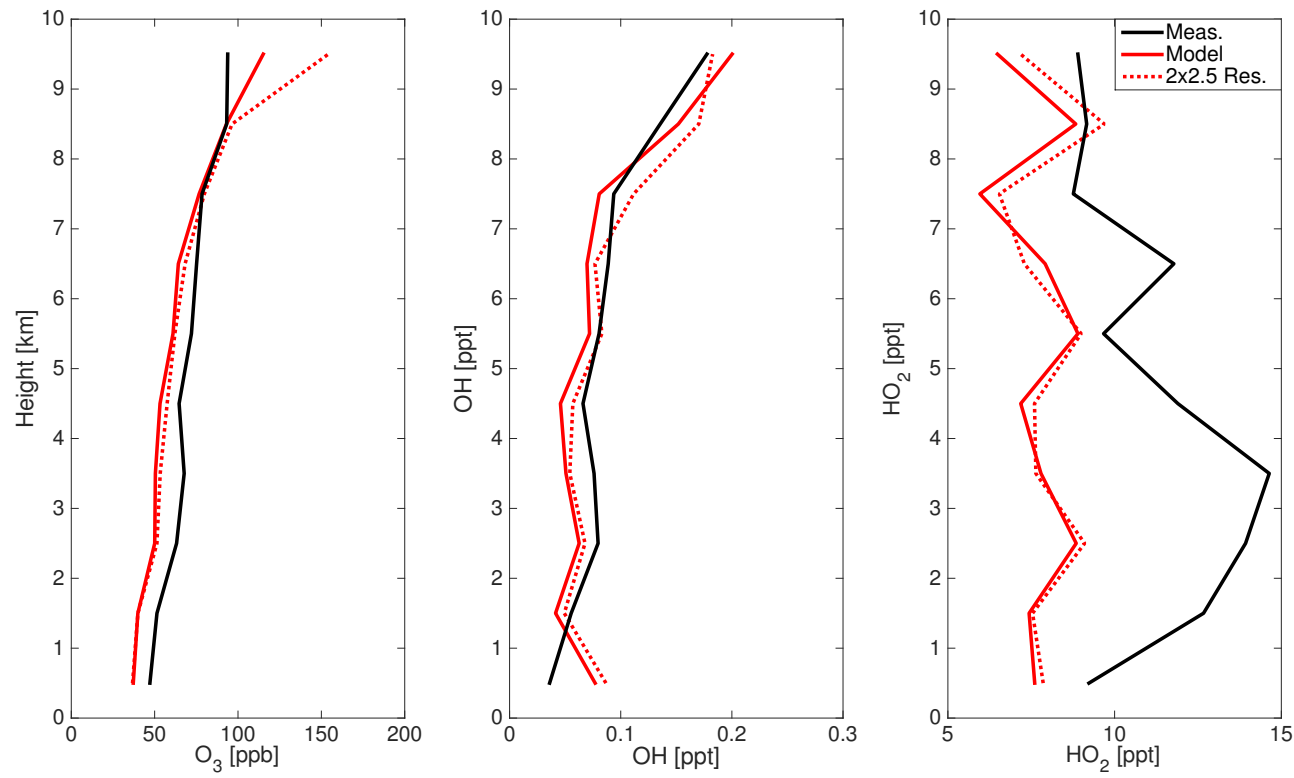

Figure S 4. Vertical profile for $4^{\circ}$ x $5^{\circ}$ median modeled (red solid), $2^{\circ}$ x $2.5^{\circ}$ median modeled (red dotted) and median measured (black) $\mathrm{O}_{3}, \mathrm{OH}$, and $\mathrm{HO}_{2}$ for Anchorage based INTEX-B flight data binned by kilometer. 

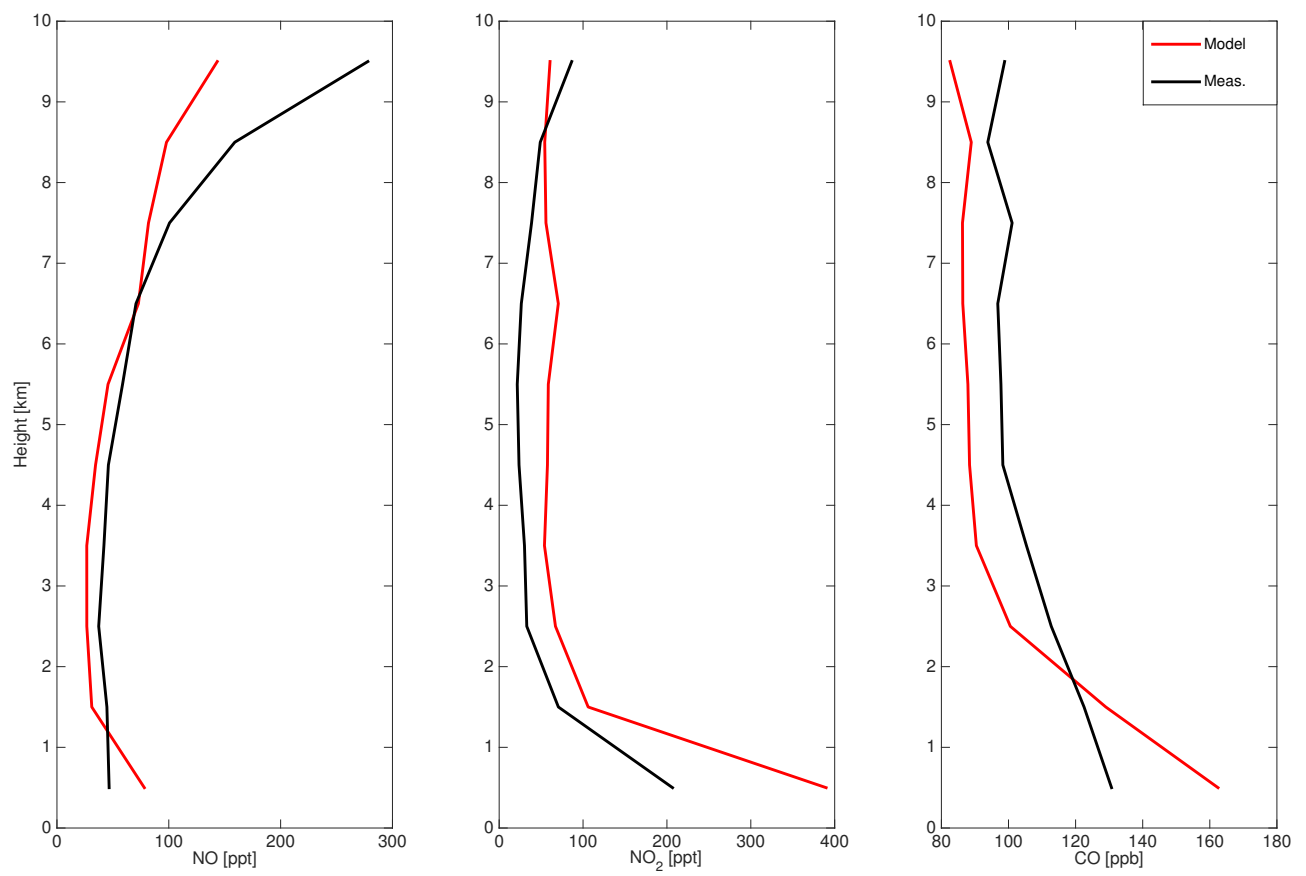

Figure S 5. Vertical profile for median modeled (red) and measured (black) NO, $\mathrm{NO}_{2}$, and $\mathrm{CO}$ for INTEX-A flight data binned by kilometer.
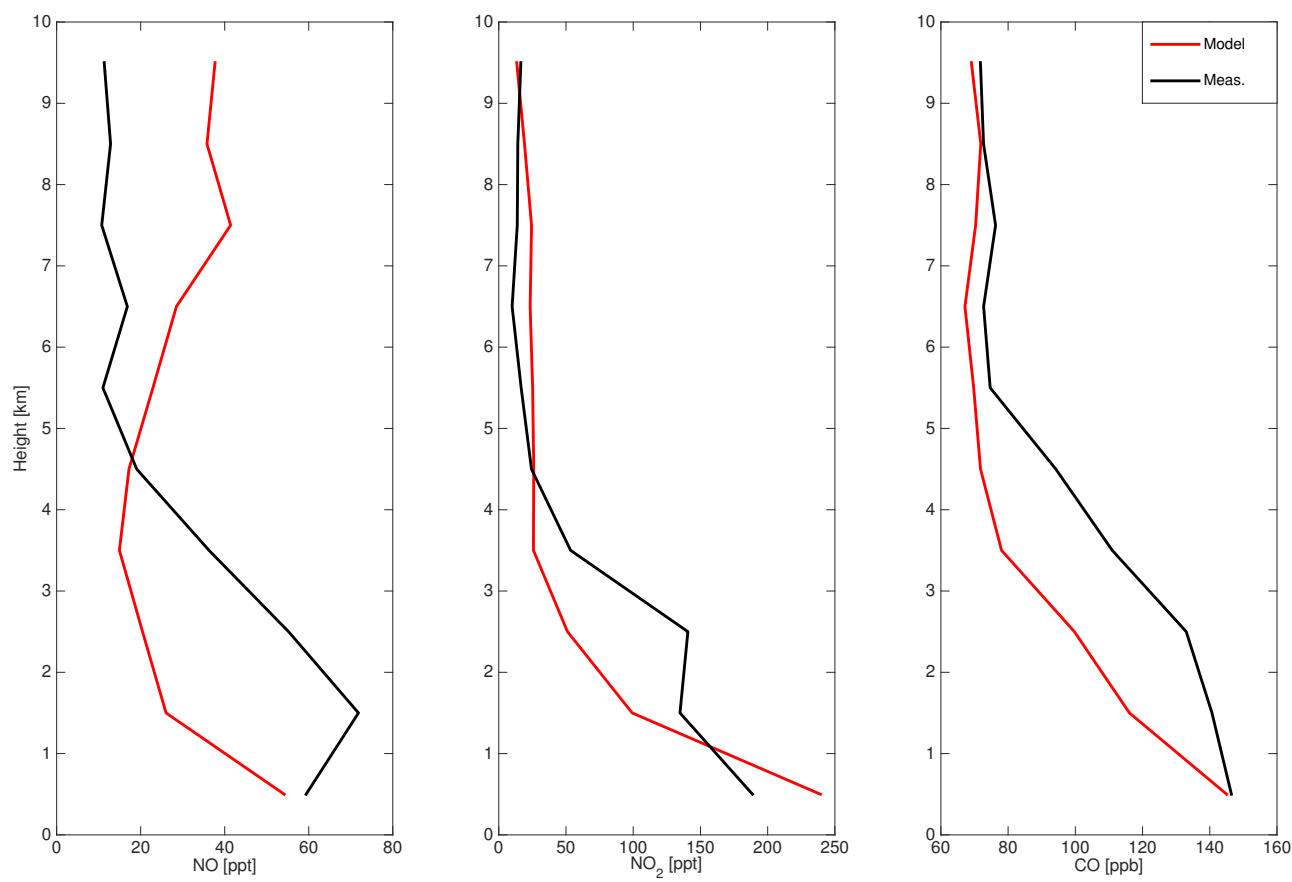

Figure S 6. Vertical profile for median modeled (red) and measured (black) NO, $\mathrm{NO}_{2}$, and CO for Houston based INTEX-B flight data binned by kilometer 

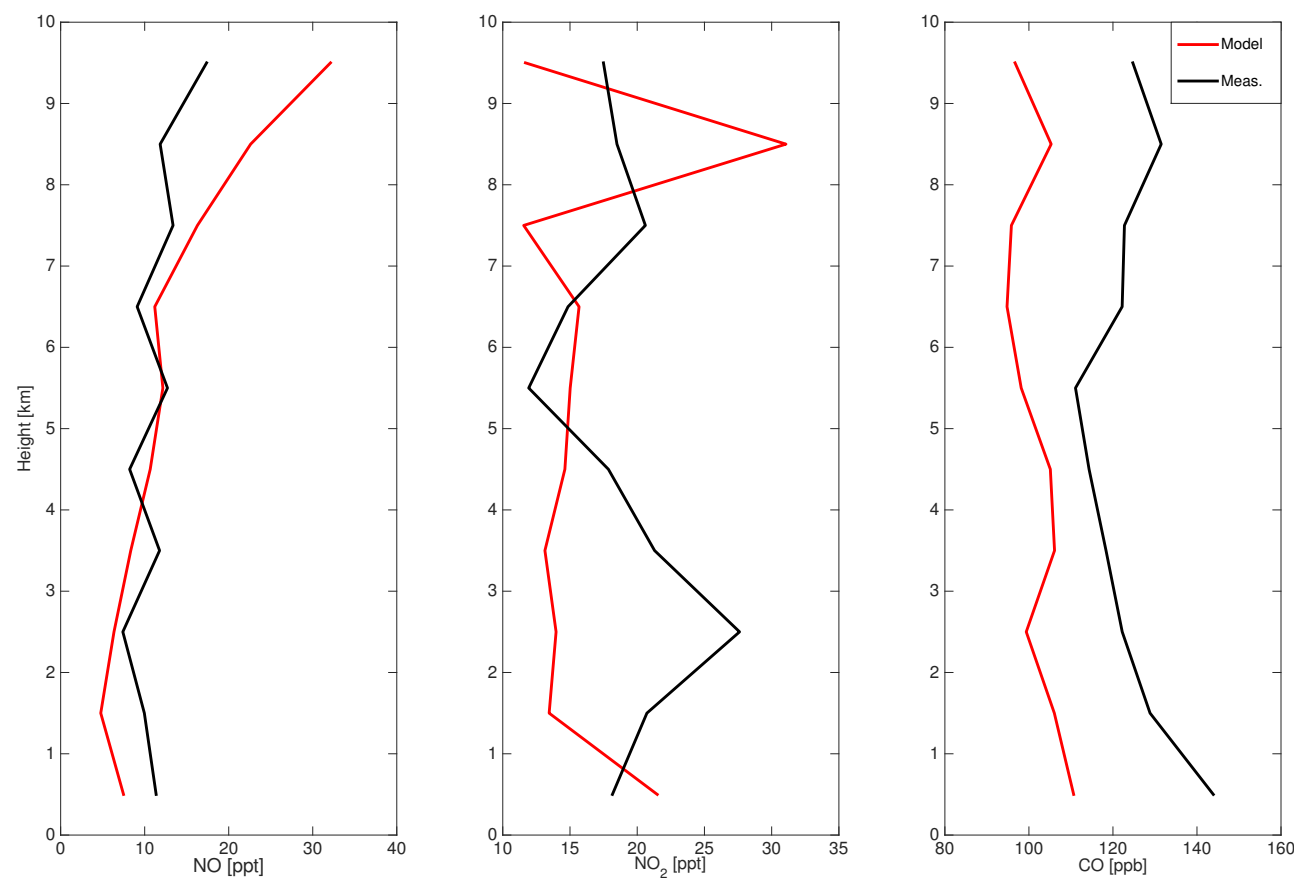

Figure S 7. Vertical profile for median modeled (red) and measured (black) $\mathrm{NO}, \mathrm{NO}_{2}$, and $\mathrm{CO}$ for Honolulu based INTEX-B flight data binned by kilometer
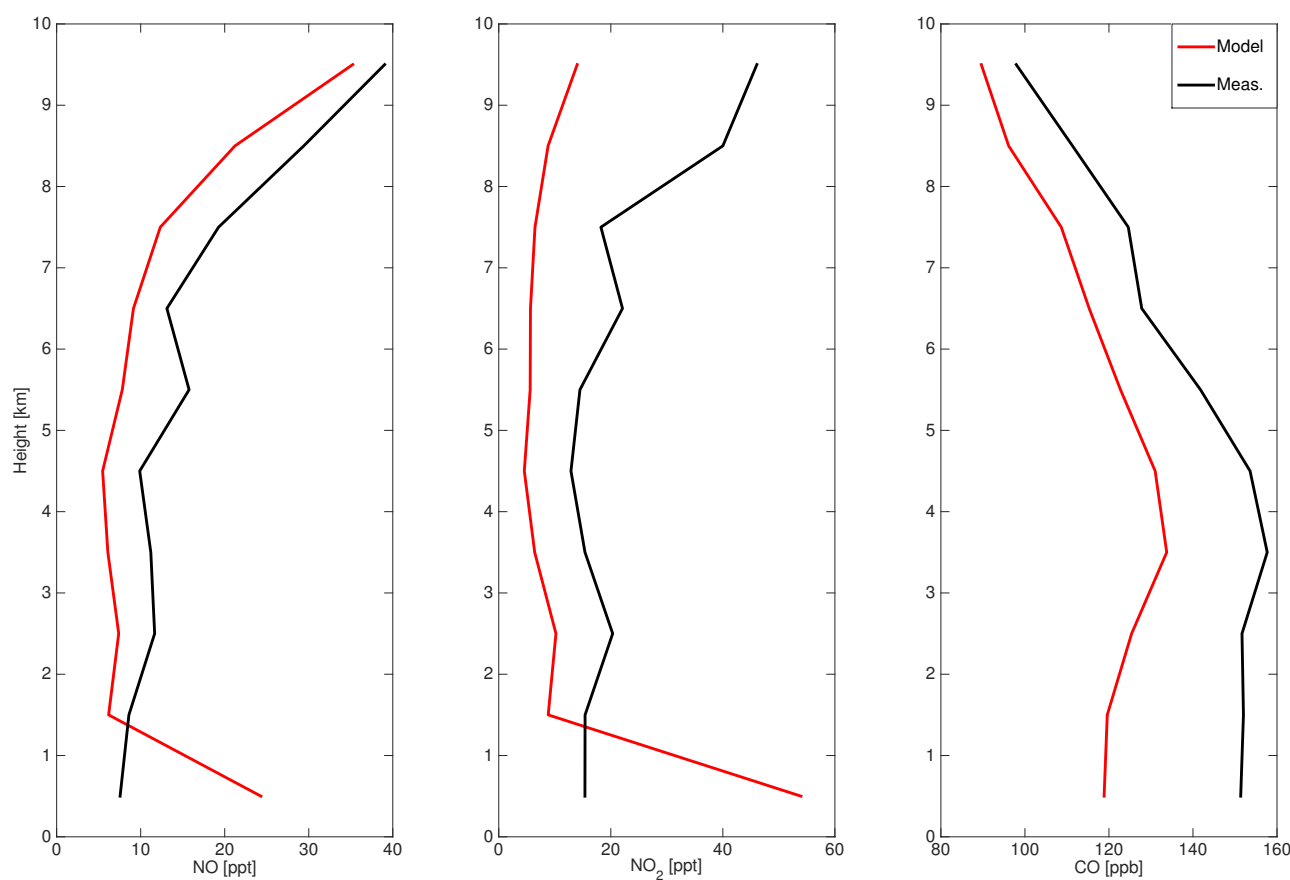

Figure S 8. Vertical profile for median modeled (red) and measured (black) NO, $\mathrm{NO}_{2}$, and CO for Anchorage based INTEX-B flight data binned by kilometer 